\title{
Unequal Incentives and Perceived Fairness in Groups
}

\author{
Gerald Eisenkopf
}

Faculty I, University of Vechta, 49377 Vechta, Germany; gerald.eisenkopf@uni-vechta.de; Tel.: +49-4441-15127

Received: 31 July 2018; Accepted: 13 September 2018; Published: 19 September 2018

check for updates

\begin{abstract}
Incentives shape how much people contribute to the welfare of a group. These incentives do not restrict the opportunities but they change the costs of contributions. This paper studies how the random assignment of such incentives affects perceived distributive justice among group members. Do people consider differences in incentives similar to unequal opportunities, that is, situations in which some people have a lower chance to make a high contribution? The results from a real effort experiment show that the economic framing of incentives matters in this context. If some people do not work for the common good because of rather large private costs, they appreciate these 'negative incentives' similarly to unequal opportunities. They do not do so, and become less egalitarian, if lower effort for the group increases the chance for private gains ('positive incentives'). Interestingly, participants reward group members who do not limit their expected contributions to the group despite adverse incentives.
\end{abstract}

Keywords: distributive justice; unequal incentives; experiment; entitlements

JEL Codes: C78; C91; D03; D31; M52

\section{Introduction}

Most people accept economic inequality if the richer person has worked harder. They are less likely to do so if mere luck determined the distribution of wealth $[1,2]$. These considerations also influence perceived distributive justice in groups. ${ }^{1}$ However, sometimes random processes influence the effort choice of people and their subsequent contribution to the benefits of a group. People become more egalitarian if group members have different contribution opportunities [8,9]. But sometimes group members just face different incentives. These diverging incentives do not limit the choice set for the decision maker. They just make otherwise desirable options rather costly for some people. The question is now whether people take such a random assignment of incentives into account when they make distribution decisions in groups. Do they consider unequal incentives as unequal opportunities because people could not alter the incentives themselves and it would have been unreasonable to bear rather high costs of contribution? Or do they stick to meritocratic considerations because unequal incentives do not limit the opportunities for effort provision? This paper addresses these questions with data from a real effort experiment.

An example may illustrate the problem. Think of two consultants who collaborate in a joint project. The project can generate a rent which has to be distributed among the consultants. Now a client appears on the stage and asks one randomly chosen consultant to work on an additional project. The request provides an incentive for the chosen consultant to pursue this task and focus less on the group project. Note that this additional incentive can be 'positive' or 'negative'. In the positive case, the consultant

1 Many studies show more acceptance of inequality in incomes if it results from hard work rather than from pure luck (see for example Burrows and Loomes [3], Hoffman, McCabe, Shachat and Smith [4], Ruffle [5] Konow [6], Durante and Putterman [7]). 
may hope for a lucrative new contract. In the negative case, she may fear losing a valuable client if she does not do so. In both circumstances it can be reasonable to pursue the additional task and reduce the effort on the joint project. Ceteris paribus such unequal incentives induce the group members to make unequal contributions to the common cause. The question is now whether this person with the altered incentives thinks that her fair share from the economic rent of the group project should be larger than her contribution and how the other group member reacts to her pursuit of incentives.

One measure for the relative influence of luck and effort is the share of people who follow the incentives. If all people ignore the request of the client from the example, only effort determines contributions to the group's project. If all people follow the client's request the impact of luck is the largest because the client assigned his request to a randomly chosen person and ignoring it seems unreasonable to everyone. Hence, in the latter case unequal incentives appear to induce unequal opportunities. ${ }^{2}$ Such a measure is in line with some prominent approaches towards distributive justice. Roemer [11], for example, argues:

"It is morally wrong to hold a person accountable for not doing something that would have been unreasonable for a person in his circumstances to have done." [11] p. 18.

For Roemer, a behavior is considered as unreasonable if other persons in the same position have refrained from doing so. Hence people should not be accountable for following the incentives if these incentives have been imposed exogenously and most of the other people in the same position would have acted likewise.

However, the proposed measure certainly provides an upper bound regarding the relative role of luck. Falk and Fischbacher [12] have a more nuanced perspective on reasonability than Roemer [11] p. 18 has. They argue that:

"(...) it is not reasonable to demand that the other person is fair to me if this implies that (relative to me) she puts herself in a disadvantageous position". [12] p. 311).

In the context of unequal incentives, this statement implies that a unilateral (and disproportionate) reduction in private earnings in order to foster group benefits is not a reasonable decision. Hence, the reasonability argument applies predominantly in the case of negative incentives such as a threat of dismissal, but not necessarily in case of positive incentive such as a chance for promotion. Meanwhile, Konow's [13] accountability criterion does not take reasonability into account. It focuses on the available alternatives only:

"The entitlement varies in direct proportion to the value of the subject's relevant discretionary variables ignoring other variables, but does not hold a subject accountable for differences in the values of exogenous variables." [13] p. 1075).

Even if the incentives themselves are exogenously determined, the behavioral consequences are clearly determined by choice. Unlike technological or cognitive restrictions incentives do not limit the feasible set of actions but affect the resulting payoffs and utility. Typically they also do not limit personal freedom. This interpretation means that unequal incentives do not lead to larger entitlements as in the case of equal opportunities.

In this paper I study perceived entitlements with results from an experiment in which two group members made either a high or a low contribution to a group account. Each group member also got some money into a private account. Participants were assigned into groups of two persons who shared a group account. In a treatment with equal opportunities-one behavioral benchmark-the size of the individual contribution depended on the performance in a real effort task. The best 50 percent of

2 The measure is related to the measurement of responsibility in Bartling and Fischbacher [10] which links individual responsibility for an allocation with the overall probability for the specific outcome. 
the subjects in a session were high contributors, the others low contributors. ${ }^{3}$ The group members negotiated about the distribution of the group account by means of an ultimatum game. The main focus of the analysis is on those groups in which the group members made unequal contributions because these groups provide the greatest scope for the application of different distribution norms.

The other treatments assigned different contribution opportunities/incentives to one randomly chosen group member. In the Unequal Opportunities Treatment one randomly chosen member in each group got a reduction in performance which limited her chances to become a high contributor. In the two treatments with unequal incentives the subjects had to choose between a reduction in performance and a change in the private account. More specifically, in the Loss Treatment one randomly chosen group member faced a loss in her private account if she did not choose to reduce the performance. In the Gain Treatment such a person had the chance to gain extra money for her private account if she reduced her performance. In both treatments the incentives were so strong that a cut in performance maximized the expected income of the decider as well as the expected aggregate income of the two persons in a group and the overall income of all subjects in a session. However, the expected impact on the other group member's income was, ceteris paribus, negative.

The results show that randomly assigned unequal incentives elicit rather meritocratic claims. Low contributors do not consider unequal incentives as unequal opportunities if they had had a chance to make themselves better off than the other group member by reducing their performance. Virtually no one applies Roemer's reasonability criterion in this context. People are more ambiguous if they are clearly worse off than others when they do not reduce their performance. In this case more than $20 \%$ of the subjects apply the reasonability criterion.

The experiment advances recent literature on distribution decisions after production periods in which random shocks distort the impact of effort on performance. Eisenkopf et al. [9] study the impact of randomized access to performance enhancing training on distribution decisions. They tend to become more egalitarian. Rubin and Sheremeta [14] show how random shocks undermine not just effort provision but also reciprocal binary relationships. Rey-Biel, Sheremeta, and Uler [15] reveal how culturally shaped general assumptions about the role of effort and luck influence charitable giving. Interestingly, these cultural differences vanish once people learn about the actual impact of effort and luck.

The paper also contributes to the literature on incentives and public good provision. Several papers have studied how randomly assigned unequal incentives affect contributions to public goods. The results on the impact of unequal incentives in public good games are mixed [16]. For example, Glöckner et al. [17] find that if contributions constitute a sacrifice for the player with higher incentives, the other team members are more inclined to cooperate than if contributions are strictly dominant for the strong player. Participants in groups with unequal incentives often punish highly incentivized people but punishment mechanisms do not enhance cooperation strongly in these circumstances [16,18]. However, the reasons for punishing people with high or low incentives are unclear in these contexts. Punishment can reflect the desire to uphold cooperation norms or a response to perceived unfair distributions that derived from the unequal allocation of incentives. The behavior in case of 'positive' incentives in this study indicates that these followers were aware of their uncooperative behavior and tried to mitigate it. In general, the rather low levels of bargaining failure across all treatments and the relatively high offers for non-followers suggest that people have a strong interest in settling any distribution conflict rather amiably. The results might differ somewhat if we take potential leadership into account. Cappelen, Reme, Sørensen and Tungodden [19] show that a moderate (but not a relatively large) compensation to a first mover is beneficial as it increases aggregate contributions to the public good.

3 Hence, some groups contained two high contributors, others two low contributors and the rest one high and one low contributors. 
The paper is structured as follows. Section 2 describes the experimental design and identifies groups that allow for the most accurate treatment comparisons. Section 3 presents the behavioral predictions. Afterwards I show the results and conclude the paper with a summary and a discussion of the results.

\section{Experimental Design}

The paper studies whether people perceive the random assignment of unequal incentives as unequal opportunities. In the context of this experiment, unequal opportunities lowered the probability of one randomly chosen group member (out of two) to make a high contribution to the common good of the group. With unequal incentives, the randomly chosen group member had-ex ante-the same contribution chances but she benefited privately from restricting her expected contributions. Hence, it is feasible, but arguably not reasonable, for that person to make the same contribution as the fellow group member. I explain the common features of the experiment in detail in the next subsection. This part also shows in detail how the design provides for equal and unequal opportunities. In the second subsection I explain the random assignment of unequal incentives and how I want to compare this assignment with the provision of unequal opportunities specifically. The subsection also contains a table that summarizes the experiment. Afterwards I discuss key features of the design and explain the interesting treatment comparisons.

\subsection{Experimental Details and the Provision of Unequal Opportunities}

Upon arrival in the lab the subjects took their randomly allocated seat, received their instructions and learned that they were in a group with another anonymous subject. The experiment then went through four stages. In the production stage (stage 1), the subjects had to count the number of zeros in tables that consisted of 150 randomly ordered zeros and ones (10 rows and 15 columns). The number of correctly counted tables defines the performance of a subject which influences her contribution to the group account (see below, stage 3). In Section 2.3 I discuss in greater detail the benefits of a real effort task for the analysis and the particular advantages of letting the subjects count zeros.

Stage 2 induced either equal or unequal opportunities. One group member had 100 points in the private account and her performance in the production stage was not manipulated in subsequent stages of the experiment. In the Equal Opportunities Treatment both conditions also held for the other group member. In the Unequal Opportunities Treatment the other subject also had 100 points in the private account. However, her performance was reduced to $75 \%$ of the number of correctly counted tables. A die determined which group member was affected by this reduction. This ex-post performance then determined individual contributions to the group account. The best $50 \%$ in a session contributed 150 points, the rest 50 points. ${ }^{4}$ Hence, some groups had a group account with 300 (100) points because both subjects were high (low) performers and contributed 150 (50) points each. In groups with a group account of 200 points, one member was a high contributor and the other a low contributor.

In stage 3, the subjects in all treatments learned about the contribution of each group member towards the group account (i.e., 50 or 150 points). Subjects never received information about the actual number of correctly counted tables of the other group member. More specifically, I did not provide any information about whether subjects with a cut in performance and a contribution of 50 points would have contributed 150 points to the group account without the cut.

In stage 4 , the subjects decided about the distribution of the group account in an ultimatum game. Each group member made a distribution proposal and stated a minimum demand. One proposal was selected randomly. If the selected proposal exceeded or matched the demand of the other player, the proposal was implemented. If the proposal was too low the group account was eliminated even if the proposal of the other group member would have been accepted. After the experiment and

4 In case of equal number of correctly counted tables, z-tree [20] chose random numbers to determine the ranks. 
an accompanying questionnaire the subjects received their earnings from the group and private accounts in cash.

\subsection{The Provision of Unequal Incentives}

The provision of unequal incentives occurred in stage 2 of the experiment (see the overview in Table 1). Like in the Unequal Opportunities Treatment, subjects in the two Unequal Incentives Treatments faced a potential cut of $25 \%$ in the number of correctly counted tables. This potential reduction affected their relative performance and in consequence their contributions to the group account. However, the subjects faced a decision about whether they were ready to forego benefits in their private account in order to avoid this performance reduction.

Table 1. The experimental design.

\begin{tabular}{|c|c|c|c|c|c|}
\hline & & $\begin{array}{l}\text { Equal } \\
\text { Opportunities }\end{array}$ & $\begin{array}{c}\text { Unequal } \\
\text { Opportunities }\end{array}$ & $\begin{array}{l}\text { Unequal Incentives } \\
\text { (Loss) }\end{array}$ & $\begin{array}{l}\text { Unequal Incentives } \\
\text { (Gain) }\end{array}$ \\
\hline & \multicolumn{5}{|c|}{ Random assignment into groups of 2} \\
\hline \multirow[b]{2}{*}{ Stage 1} & \multicolumn{5}{|c|}{ Production Stage: Real Effort Task } \\
\hline & \multicolumn{5}{|c|}{$\begin{array}{l}\text { Counting zeros in tables, as in Abeler, Falk, Götte and Huffman [21]. } \\
\text { The number of correctly counted tables determines undistorted performance. }\end{array}$} \\
\hline \multirow{3}{*}{ Stage 2} & \multicolumn{5}{|c|}{ Treatment Intervention (relevant for one of the two group members) } \\
\hline & \multicolumn{2}{|l|}{ Altern. 1} & $\begin{array}{l}\text { Keep } 100 \text { points in } \\
\text { private account } \\
\text { Lose } 25 \% \text { of } \\
\text { performance }\end{array}$ & $\begin{array}{l}\text { Keep } 100 \text { points in } \\
\text { private account } \\
\text { Lose } 25 \% \text { of } \\
\text { performance }\end{array}$ & $\begin{array}{l}\text { Win additional } \\
1100 \text { Points for private } \\
\text { account }(10 \% \text { prob.) } \\
\text { Lose } 25 \% \text { of performance }\end{array}$ \\
\hline & Altern. 2 & - & $\overline{\text { (no choice) }}$ & $\begin{array}{l}\text { Lose } 100 \text { points in } \\
\text { private account. } \\
\text { Keep full performance }\end{array}$ & $\begin{array}{l}\text { Keep } 100 \text { points in } \\
\text { private account. } \\
\text { Keep full performance }\end{array}$ \\
\hline Stage 3 & \begin{tabular}{rr}
\multicolumn{2}{l}{ Informatio } \\
- & Det \\
& (Thr \\
- & Perf \\
- & Rev \\
- & Con \\
$\bullet$ & $\bullet$
\end{tabular} & \multicolumn{4}{|c|}{$\begin{array}{l}\text { Determination of private account in the Gain Treatment if the relevant person has chosen Alternative } 1 . \\
\text { (Throw of a die). } \\
\text { Performance reduction of } 25 \% \text { (if applicable). } \\
\text { Revelation of relevant decisions, contributions to the group account and private payoffs. } \\
\text { Contribution to the group account according to the number of correctly counted tables: } \\
\text { - } \quad 150 \text { points: top } 50 \% \text { in a session (after reduction) } \\
\text { - } \quad 50 \text { points: the remaining participants }\end{array}$} \\
\hline \multirow[t]{2}{*}{ Stage 4} & \begin{tabular}{lr}
\multicolumn{2}{c}{ Bargainin } \\
- & Eacl \\
- & Eacl \\
- & One \\
- & If th \\
- & Oth
\end{tabular} & \multicolumn{4}{|c|}{$\begin{array}{l}\text { Each group member makes a distribution proposal. } \\
\text { Each group member states a minimum demand. } \\
\text { One proposal is selected randomly. } \\
\text { If the selected proposal exceeds the demand of the other player, it is implemented. } \\
\text { Otherwise the group account is eliminated. }\end{array}$} \\
\hline & & Ques & onnaire, Payment, Sul & cts leave the laboratory. & \\
\hline
\end{tabular}

The two treatments with unequal incentives differ with respect to the monetary consequences of the decision. In the Loss Treatment the subjects had to decide whether they were ready to give up the 100 points in their private account in order to avoid a $25 \%$ cut in the number of correctly counted tables. The alternative was to keep the 100 points and accept the $25 \%$ cut in performance. In the Gain Treatment the subjects had to decide whether they were ready to give up a potential increase in the private account in order to avoid the $25 \%$ cut in the number of correctly counted tables. The alternative was to gain another 1100 points in the private account with a probability of $10 \%$ and accept the $25 \%$ cut in performance.

In both Unequal Incentives Treatments, the decision was relevant for exactly one of the two group members. The other group member kept the full performance and 100 points in the private account. A die determined whose decision was the relevant one. In the Gain Treatment a ten-sided die also determined whether a person received 1100 points if she had decided to have her performance cut 
by $25 \%$ and if that decision became relevant. In both treatments subjects received information about whose decision was relevant and its result. They also learned about the size of the private account of the other group member.

In both treatments subjects maximize their own payoff and aggregate payments if they accept the cut of $25 \%$ of the correctly counted tabels. In the Gain Treatment, I opted for a lottery because a pre-defined gain would have restricted a comparison across treatments. With the lottery, the focus is on those $90 \%$ of the deciders who followed the incentives but have 100 points in their private account nevertheless. The prize of 1100 points (rather than 1000) accounts for some potential moderate degree of risk aversion among the subjects.

\subsection{Discussion of the Design}

At this point it is worthwhile to emphasize three key characteristics of the experimental design. First the reader may consider the real effort task as unnecessarily cumbersome. However, in comparison to monetary investments the choice of a real effort task actually simplifies the analysis of the subsequent distribution decisions. In the negotiation stage people do not have to take any differences in monetary investments into account. Moreover, subjects decide about their effort in the production phase before any role assignment. Hence, the results should not show any differences in pre-reduction performance across the roles. Furthermore, Abeler et al. ([21] p. 473) describe the advantages of counting zeros: it "does not require any prior knowledge, performance is easily measurable, and there is little learning possibility; at the same time, the task is boring and pointless, and we can thus be confident that the task entailed a positive cost of effort for subjects". Since this task is (psychologically) costly and implies no intrinsic value for the subjects or the experimenter it enforces a sense of entitlement regarding the distribution of the group account. At the same time, I expect no differences in the performance across treatments. While the marginal benefits of effort differ across the treatments, I expect them always to be larger than the marginal psychological costs of effort because the production stage is sufficiently short.

Second, the incentives for a reduced contribution to the group account are very strong in the treatments with unequal incentives. I chose these extreme values because it should be a clearly reasonable and indeed dominant strategy to follow the incentives. Reducing the performance is also efficient at the group level. Hence it is not unreasonable to act in this way.

Third, the minimum demand in the ultimatum game measures what a subject perceives to be her own minimum entitlement. The ultimatum game also provides for measure of conflict between the group members. Conflicts occur when the minimum demand of one group member is incompatible with the distribution offer of the other member.

Regarding the procedural details, I conducted 26 sessions with a total of 722 subjects. All sessions took place between June 2012 and December 2013 at the Lakelab at the University of Konstanz. Subjects were students from the University of Konstanz who were recruited with the software "ORSEE" [22]. The experiments were computerized with the software "z-Tree" [20]. Each subject participated in one of the treatments only. They received written instructions and comprehension questions that had to be answered correctly before the experiment could start. The sessions lasted approximately $60 \mathrm{~min}$. All subjects received their payment privately at the end of their session.

\subsection{Relevant Treatment Comparisons}

\subsubsection{Comparison of Demands}

The groups in the experimental treatments can differ with respect to the private earnings, contribution patterns, and the size of the group account. Regarding the last criterion, we can obtain groups with a group account of 100 points (if each group member contributes 50 points), 200 points (if one group member contributes 50 points and the other 150 points), and 300 points (if each group member contributes 150 points). 
The groups with heterogeneous contributions are the focus of this study. The potential variation between these groups is enormous even though the size of the group account is 200 points in all these groups. In the Unequal Opportunities Treatment we can observe the following group types. Either the group member with worse opportunities (i.e., the one with a cut in performance) contributes 50 points, while the other group member contributes 150 points. Alternatively the group member with worse opportunities contributes 150 points, while the other group member provides 50 points. Of course I expect the first group type to occur more frequently because the opportunities are assigned randomly.

In the Unequal Incentives Treatments the variation of potential group types is larger. There is exactly one person in each group for whom the incentivized decision regarding the private account and the performance reduction is relevant. This person can follow the incentives by choosing alternative 1 over alternative 2 (in which case I call her a follower) or she can leave the performance untouched at the expense of her private account (in which case I call her a non-follower). Ignoring the ex-post irrelevant choices of the other group members we obtain eight different group types in the Unequal Incentive Treatments. However, most groups are likely to have the following characteristics: The follower contributes 50 points, the other group member 150 points. The follower has 100 points in her private account. The incentives are strong, so most people will follow the incentives. Because the followers are disadvantaged they are more likely to contribute less to the group account than the other group member. Because people in the Gain Treatment win an additional 1100 points with a probability of $10 \%$ only, most followers will have 100 points in their private account when they enter the ultimatum game.

In summary the following groups with 200 points in their group account provide for the most prominent and interesting treatment comparison:

1. Equal Opportunities Treatment: All groups with asymmetric contributions.

2. Unequal Incentives (Gain): All groups in which a follower with 100 points in her private account contributes 50 points, while the other group member contributes 150 points.

3. Unequal Incentives (Loss): All groups in which a follower with 100 points in her private account contributes 50 points, while the other group member contributes 150 points.

4. Unequal Opportunities: All groups in which the group member with worse opportunities contributes 50 points, the other group member 150 points.

Given these subgroups two aspects can determine treatment differences. The behavior of the subjects may change or we observe a selection process into the different subsamples within the treatments. The result section will disentangle these different processes.

\subsubsection{Comparison of Offers}

For the assessment of fairness preferences, the offers in an ultimatum game typically do not provide clean information because strategic considerations about what the other player is ready to accept also influence the choice of offer. However, the design of this experiment allows for some comparisons in the Gain and Loss Treatments. In these treatments we can compare the offers of those people whose own decisions regarding following the incentives have turned out to be irrelevant. Since these hypothetical followers and non-followers obtained randomly allocated group members with the same observable characteristics, their beliefs should not differ if one assumes common knowledge about rational agents. Hence, any difference in offers between followers and non-followers is due to different fairness preferences.

\section{Behavioral Predictions}

\subsection{Effort, Luck and Minimum Demands}

The predictions focus on the differences in minimum demands across treatments in case of unequal contributions. In every treatment a homo oeconomicus will set her minimum demand to 0 points and accept every offer. Outcome-oriented models of social preferences like Fehr and Schmidt [23] or 
Bolton and Ockenfels [24] also do not predict any aggregate differences in demands, neither between high and low contributors nor across the treatments. High and low contributors have the same bargaining position and the size of the private account does not differ across the relevant comparison groups (it is always 100 points for each group member in these groups). These observations are not in line with the overwhelming empirical insights from dictator games. Dictator choices are less egalitarian and more meritocratic when effort rather than luck determines the pie size that has to be distributed. ${ }^{5}$ Eisenkopf et al. [9] make similar observations for minimum demands in the context of a variant of the ultimatum game.

Cox, Friedman, and Gjerstad [29] explain such behavior in the ultimatum game via differences in perceived entitlements. More specifically, high contributors will have a higher sense of entitlement than low contributors. This difference in perceived entitlements is smaller if luck rather than effort determines the source of income. If the perceived entitlement is higher than the offer, the receiver will reject the offer. In the Equal Opportunities (EO) Treatment high (low) contributors fully earn their high (low) position. The Unequal Opportunities Treatment (UO), provides the setting in which luck has the largest impact on the individual contribution. Hence, the order of entitlements implies the following predictions.

Hypothesis H1. (Minimum Demands in the Benchmark Treatments): (a) In all treatments high contributors make higher claims than low contributors; (b) Low contributors in the Equal Opportunities Treatment make lower claims than low contributors in the Unequal Opportunities Treatment.

\subsection{Effort and Luck in Treatments with Unequal Incentives}

The predictions for the Gain and Loss Treatments focus at first on the decision about whether to follow the randomly assigned incentives. This response to incentives signals a person's intentions. Intentions-based models of social preferences like Falk and Fischbacher [12] claim that we can infer a person's intentions by comparing her choice with the decision of other people in the same context (see also McCabe, Rigdon, and Smith [30]). With an increasing number of people deciding against the incentives, the intentions behind choosing the payoff maximizing outcome seem rather malign. On the other hand, if all people follow the incentives and suffer from a subsequent reduction in expected, it is more difficult to attribute negative intentions. Apparently, the choice set does not offer a sensible alternative. In such a context, unequal incentives resemble unequal opportunities.

In both treatments (Gain and Loss) it is clearly payoff maximizing to reduce the performance. Such a decision also increases the aggregate welfare of the group even if it decreases the expected size of the group account. Regarding all participants in a session it is also the efficient decision because the aggregate value of all group accounts in a session is fixed. However, people consider avoiding a loss at the expense of others as less malign than attempting to get an additional benefit [31]. Hence, fewer people will follow the incentives in the Gain Treatment than in the Loss Treatment which implies that actual followers signal rather malign intentions.

Hypothesis H2. (Response to Incentives): (a) Most subjects in the Gain and Loss Treatment will reduce their performance; (b) In the Gain Treatment the share of people who choose to reduce their performance is lower than in the Loss Treatment.

The pursuit of incentives provides a straight-forward way of assessing the relative status of high and low contributors in the Gain and Loss Treatments. According to this criterion the impact of luck

5 Examples include Cherry, Frykblom and Shogren [25], Cappelen et al. [8], Oxoby and Spraggon [26], Lefgren, Sims and Stoddard [27], Tonin et al. [28]. 
increases in the number of people who follow the randomly assigned incentives. It determines to which extent people perceive unequal incentives as unequal or equal opportunities.

Hypothesis H3. Minimum demands of low contributors in both Unequal Incentive Treatments are higher than in the Equal Opportunities Treatment. They are ordered as follows across the treatments:

$$
\text { Equal Opportunities < Gain < Loss } \leq \text { Unequal Opportunities }
$$

As mentioned in the introduction, not all measures of distributive justice allow for such differentiated appreciation of status. Konow's [13] accountability criterion would capture all differences in contributions in the Unequal Incentives Treatments as endogenous outcomes since both high and low contributors had the same opportunities to contribute. With this perspective, the order of minimum demands of low contributors would be as follows:

$$
\text { Equal Opportunities }=\text { Gain }=\text { Loss }<\text { Unequal Opportunities }
$$

\section{Results}

I present the results in the following order. At first I test the hypotheses with the data from the experiment. Then the paper has a closer look at whether the key treatment differences in the relevant subsamples derive from changes in behavior or self-selection of subjects into the different subsamples. Afterwards I look at differences in offers. Appendix B contains tables about claims in case of equal contributions. They show no systematic differences across treatments and subsamples.

\subsection{Task Performance and Incentive Impact}

Table 2 documents the average performance of subjects in the different treatments. As expected, Wilcoxon rank-sum tests reveal no significant differences between the treatments. The table also shows the effectiveness of the different incentive schemes. After production all subjects in the treatments with unequal incentives had to decide whether they accepted a cut in their performance in order to get a potential gain or avoid a loss on their private account. Most people followed the incentives. However, while $89 \%$ accepted that cut in the Loss Treatment only $67 \%$ did so in the Gain Treatment. According to the Fisher Exact test this difference is significant $(p<0.01)$. These results support Hypotheses H2(a) and $\mathrm{H} 2(\mathrm{~b})$.

Table 2. Average performance and incentive impact across the treatments.

\begin{tabular}{cccccc}
\hline & $\begin{array}{c}\text { Equal } \\
\text { Opportunities }\end{array}$ & $\begin{array}{c}\text { Unequal } \\
\text { Incentives (Gain) }\end{array}$ & $\begin{array}{c}\text { Unequal } \\
\text { Incentives (Loss) }\end{array}$ & $\begin{array}{c}\text { Unequal } \\
\text { Opportunities }\end{array}$ \\
\hline \multirow{2}{*}{$\begin{array}{c}\text { Number of correctly } \\
\text { counted tables }\end{array}$} & Mean (st. dev.) & $14.21(4.91)$ & $14.09(4.71)$ & $13.64(5.27)$ & $14.42(5.11)$ \\
\cline { 2 - 6 } & Median & 14 & 13 & 14 & 15 \\
\hline Followers * & n.a. & 185 & 147 & n.a. \\
\hline N & 140 & 276 & 166 & 140 \\
\hline
\end{tabular}

${ }^{*}$ Followers are subjects who decide in line with the incentives.

Result 1 (Response to Incentives)

(a) Most subjects in the Gain and Loss Treatment reduce their performance.

(b) In the Gain Treatment the share of people who choose to reduce their performance is lower than in the Loss Treatment.

\subsection{Bargaining Behavior}

The large share of people in the Gain Treatment who did not follow the incentives required a substantially larger subject pool in this treatment. First of all, it required more subjects to get 
sufficient data for the treatment comparison. Furthermore, more data was necessary to investigate how the reaction to the incentives affected the decisions of the group members. These choices affect the number of comparable observations that have been defined in Section 2.4. Table 3 shows the number of all groups and the number of the comparable groups (bold letters). Appendix B provides a detailed summary of all subsamples in each treatment.

Table 3. Number of (relevant) groups in the different treatments.

\begin{tabular}{|c|c|c|c|c|c|}
\hline & & $\begin{array}{c}\text { Equal } \\
\text { Opportunities }\end{array}$ & $\begin{array}{c}\text { Unequal } \\
\text { Incentives (Gain) }\end{array}$ & $\begin{array}{c}\text { Unequal } \\
\text { Incentives (Loss) }\end{array}$ & $\begin{array}{c}\text { Unequal } \\
\text { Opportunities }\end{array}$ \\
\hline \multicolumn{2}{|c|}{ Group account 200 points } & 34 & 72 & 47 & 40 \\
\hline \multirow[b]{2}{*}{ Subsamples } & $\begin{array}{l}\text { Disadvantaged member } \\
\text { contributes } 50 \text { points }\end{array}$ & - & - & - & 33 \\
\hline & $\begin{array}{l}\text { Follower contributes } 50 \text { points. } \\
\text { The follower has } 100 \text { points in } \\
\text { her private account. }\end{array}$ & - & 31 & 31 & \\
\hline \multicolumn{2}{|c|}{ Group account 300 points } & 18 & 33 & 18 & 15 \\
\hline \multicolumn{2}{|c|}{ Group account 100 points } & 18 & 33 & 18 & 15 \\
\hline
\end{tabular}

The bold numbers show those groups that constitute the samples for the relevant treatment comparisons. Followers are subjects who decide in line with the incentives. Appendix B provides detailed information about subsample in the different treatments.

The hypotheses focus on the different claims in case of unequal contributions (i.e., one group member contributes 50 points, the other 150). For the comparisons I study the above mentioned relevant subsamples (in bold letters) and report p-values from two-sided Wilcoxon rank-sum tests.

Table 4 shows the minimum demands of the relevant low and high contributors. Overall the results confirm that neither selfish preferences nor inequity aversion explain the claims appropriately. I find strong support for the proportionality hypothesis $\mathrm{H} 1$ as high contributors make stronger claims than low contributors. The differences in minimum claims between high and low contributors are highly significant in all treatments (all $p$-values $<0.001$ ) even though high and low contributors have (in theory) equal bargaining power. The difference between the minimum claims of high contributors across the treatments is somewhat smaller and they vary stronger than the claims of low contributors. They do not differ across the treatments (all $p$-values $>0.5$ ). Status differences are not so important for high contributors if they get at least $50 \%$ group account. Regarding the low contributors in the benchmark treatments the claims are ordered as predicted in Hypothesis H1(b). They are at the lowest in the Equal Opportunities Treatment, while the Unequal Opportunities Treatment provides for the highest claims. The difference between these two benchmarks is significant $(p=0.011)$.

Table 4. Minimum demands in case of unequal contributions.

\begin{tabular}{ccccc}
\hline & Equal Opportunities & Unequal Incentives (Gain) & Unequal Incentives (Loss) & Unequal Opportunities \\
\hline All Low Contributors & $\mathbf{5 4 . 0 8 ( 1 5 . 5 9 )}$ & $59.46(20.44)$ & $58.09(19.69)$ & $62.73(20.26)$ \\
\hline Relevant Subsample & - & $\mathbf{5 6 . 1 6 ( 2 0 . 5 1 )}$ & $\mathbf{6 0 . 6 5 ( 1 6 . 2 1 )}$ & $\mathbf{6 4 . 6 7 ( 2 1 . 4 8 )}$ \\
\hline All High Contributors & $\mathbf{1 0 1 . 0 3 ( 2 8 . 6 5 )}$ & $102.63(25.13)$ & $100.40(25.98)$ & $99.23(28.90)$ \\
\hline Relevant Subsample & - & $\mathbf{9 5 . 4 8 ( 2 8 . 8 5 )}$ & $\mathbf{9 9 . 9 7 ( 2 1 . 8 0 )}$ & $\mathbf{9 9 . 0 6 ( 2 5 . 9 6 )}$ \\
\hline
\end{tabular}

The bold numbers show those groups that constitute the key samples for our treatment comparisons. Standard deviations are in parentheses. Followers are subjects who decide in line with the incentives.

Result 2 (Minimum Demands in the Benchmark Treatments)

(a) In all treatments high contributors make higher claims than low contributors.

(b) Low contributors in the Equal Opportunities Treatment make lower claims than low contributors in the Unequal Opportunities Treatment.

In the Gain Treatment low contributors do not consider unequal incentives as unequal opportunities $(p=0.049)$. Their claims are close to those in the Equal Opportunities Treatment 
which is not in line with Hypothesis H3. In the Loss Treatment the average minimum demands of low contributors differ from those in Equal Opportunities Treatment $(p=0.055)$ but not from the ones in the Unequal Opportunities Treatment $(p=0.287)$. Given the seemingly large differences in mean average demands this last result seems surprising and I disentangle it in more detail below.

Result 3: Minimum Demands of Low Contributors in Both Unequal Incentive Treatments Do Not Differ Significantly from Those in the Equal Opportunities Treatment. They Are Ordered As Follows across the Treatments

$$
\text { Equal Opportunities } \leq \text { Gain } \leq \text { Loss } \leq \text { Unequal Opportunities }
$$

with

$$
\text { Gain < Unequal Opportunities and Equal Opportunities < Loss }
$$

The relatively large variation of claims within each treatment in Table 4 already suggests that people differ with respect to their perceived entitlements. Such a heterogeneity is also well known in the literature [8]. We explore how this heterogeneity affects the treatment differences. Figure 1 shows the cumulative distribution of minimum claims of the relevant low contributors. Claims smaller or equal to 50 points can be considered as meritocratic because these participants do not demand more than they have contributed and do not take differences in status into account. Only claims larger than 50 points do so.

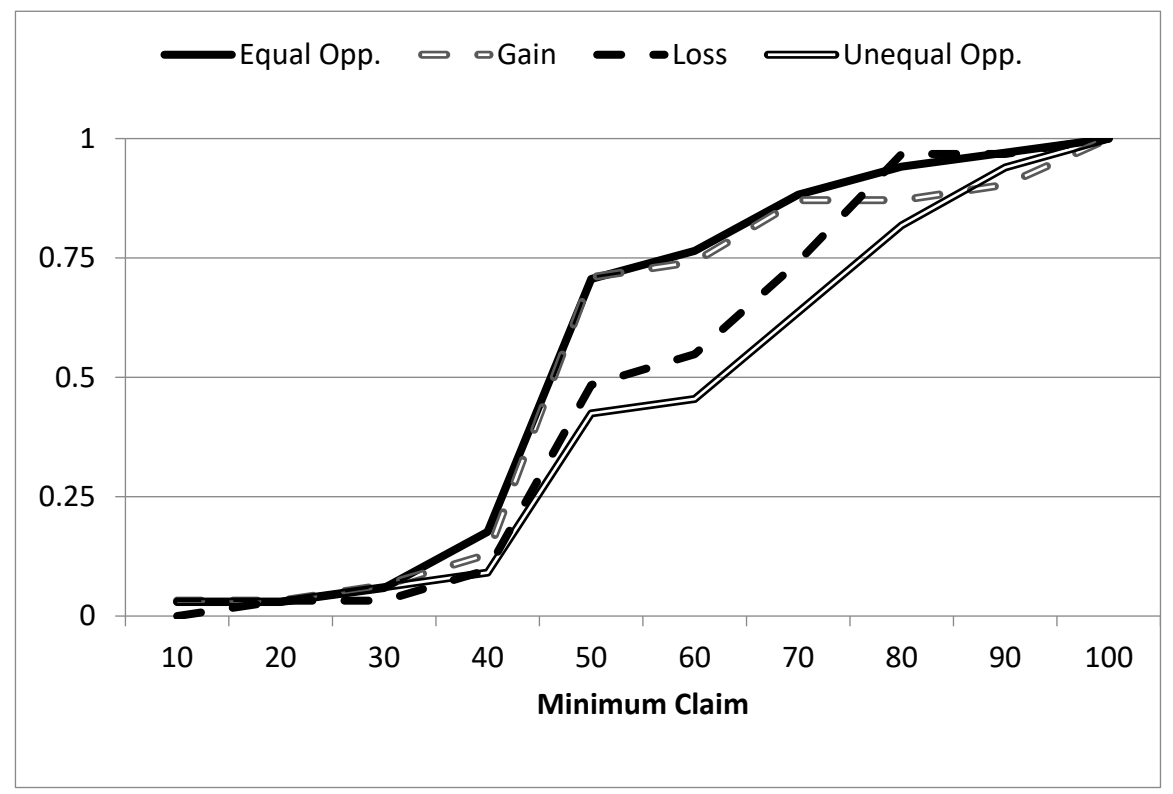

Figure 1. Cumulative distribution of minimum claims of low contributors across the treatments.

Figure 1 reveals that the treatment differences are not stronger because at least $40 \%$ of low contributors accept meritocratic distributions in any treatment. Hence, our status-based theoretical framework can explain the behavior of $60 \%$ of the subjects in the Unequal Opportunities and Incentive Treatments at most. Given that some people also apply rather strict egalitarian claims even in the case of equal opportunities the scope for treatment effects is rather small. In the Equal Opportunities Treatment, the share of meritocratic claims is much higher than in the Unequal Opportunities Treatment. (70.5\% vs. $42.4 \% ; p<0.02$ according to the Fischer-Exact Test). In the Gain Treatment $70.9 \%$ make meritocratic claims. Hence the random assignment of potential gains induces virtually no one to consider status differences. At the same time, only $48.4 \%$ of the low contributors in the Loss Treatment make meritocratic claims. Hence, more than $20 \%$ of low contributors take status into account once the incentives are not about potential gains any more. 
The figure also provides some information about the differences between the Loss Treatment and the Unequal Opportunities Treatment. The above mentioned insignificant test results regarding the differences in minimum claims of low contributors mainly derive from the fact that the share of meritocratic claims is about the same in both treatments (48.4\% vs. $42.4 \%)$. However, the non-meritocratic demands (all demand $>50$ points) differ to some extent. They are, on average, 73.75 points in the Loss Treatment (16 observations) and 79.68 points in the Unequal Opportunities Treatment (19 observations). The difference is significant at the $10 \%$ level $(p=0.092)$ and indicates that even in the Loss Treatment low contributors do not consider unequal incentives entirely as unequal opportunities. ${ }^{6}$

\subsection{Selection Effects or Change in Behavior}

In this subsection I study whether the treatment differences in the minimum demands of low contributors derived from selection effects or behavioral changes. In the Unequal Opportunities Treatment some high performers became low contributors because of the randomly assigned reduction in performance. Without this handicap some low performers would have been high contributors. A behavioral effect of the treatment implies that the difference in claims occurred because the handicap induced disadvantaged people to increase their claim. A selection effect implies that slightly more productive participants make higher claims than the less productive. In this case the treatment difference in minimum demands derives from the fact that the low contributors are more productive in the Unequal Opportunities Treatment. Hence, any empirical support for the selection effect rests on the idea that minimum claims increase in the undistorted productivity of the person. Hence, a test on selection effects studies high performers who became low contributors and compares their minimum claims with 'true' low performers in the treatment with unequal opportunities. According to the rank-sum test these demands do not differ significantly in any treatment $(p=0.98)$.

The results documented in Table 5 also do not provide support for such a selection effect. Model 1 in this table shows how minimum claims of high and low contributors (above and below median performers) depend on their performance in their real effort task. The relevant coefficient is actually insignificantly negative. Model 2 distinguishes within the high and low contributors. The 2nd and 3rd quartile show those subjects whose contributions could have been altered in the Unequal Opportunities Treatment. Even within these subgroups the actual impact of performance on claims is effectively zero. Hence, the differences in Treatments do not derive from productivity dependent selection effects.

Table 5. OLS Estimation on the impact of task performance on minimum claims of high and low contributors in the Equal Opportunities Treatment.

\begin{tabular}{ccc}
\hline & Model 1 & Model 2 \\
\hline Performance & $-1.049(0.853)$ & $1.657(3.400)$ \\
3rd Quartile (Performance $\geq 10)$ & & $-4.861(43.556))$ \\
Perfomance $\times$ 3rd Quartile & & $-0.958(4.477)$ \\
2nd Quartile/Above Median & $41.360^{*}(24.476)$ & $49.973(102.820)$ \\
Perfomance $\times$ Above Median & $0.757(1.504)$ & $-3.389(5.477)$ \\
1st Quartile (Performance $\geq 10)$ & & $67.746(74.387)$ \\
Perfomance $\times$ 1st Quartile & & $-2.275(4.476)$ \\
Constant & $65.040 * * *(9.857)$ & $47.486^{* *}(22.609)$ \\
$\mathrm{N}$ & 68 & 68 \\
$\mathrm{R}^{2}$ & 0.512 & 0.524 \\
\hline
\end{tabular}

Significance levels: ${ }^{* * *} p<0.01 ;{ }^{* *} p<0.05 ;{ }^{*} p<0.1$.

6 All other treatment comparisons in minimum demands differentiated for meritocratic and non-meritocratic claims turn out as insignificant. 
Now I focus on whether the treatment differences in minimum demands of low contributors between Unequal Opportunities Treatment and the Gain Treatment derive from selection effects or changes in behavior. Such a selection effect would support the intuitive claim that minimum demands in the Gain Treatment are lower because people who follow the incentives are more ready to accept inequality than those who do not follow.

This reasoning requires that people who do not follow the incentives make particularly high minimum demands. To test whether this is correct it is helpful to recall that these subjects in the Gain Treatment are comparable to low contributors from the Equal Opportunities Treatment. They kept their full performance and 100 points in their private account. However, in case of the investigated selection effect they should have made much higher minimum demands.

Table 6 shows that this is not the case. The minimum demand of these low-contribution non-followers does not differ from those in the Equal Opportunities Treatment. Nor does it differ from low contributors in the Gain Treatment who chose to reduce their performance (all $p$-values $>0.37$ ). Hence these results imply that treatment differences in the minimum demands of low contributors between the Gain Treatment and Unequal Opportunities Treatment derive from behavioral changes rather than selection effects.

Table 6. Minimum demands of low contributors in the Gain Treatment in case of unequal contributions, differentiated for followers and non-followers.

\begin{tabular}{cccc}
\hline & \multirow{2}{*}{ Equal Opportunities Treatment } & \multicolumn{2}{c}{ Unequal Incentives (Gain) } \\
\cline { 3 - 4 } & & Follower & Non-Follower \\
\hline Demand (St. Dev) & $54.08(15.59)$ & $56.16(20.51)$ & $55.71(19.10)$ \\
\hline $\mathrm{N}$ & 34 & 31 & 14 \\
\hline
\end{tabular}

Result 4: Self-Selection Effects Do Not Explain the Treatment Differences in Minimum Demands of Low Contributors

\subsection{An Analysis of Offers and Rejection Rates}

Now the focus shifts to the offers. Table 7 shows the distribution offers of high and low contributors in the different treatments. In all treatments low contributors make significantly higher offers than high contributors (all $p$-value $<0.001$ ). The offers in the two benchmark treatments (Equal and Unequal Opportunities Treatments) do not differ significantly across the treatments. This holds for offers of both high and low contributors ( $p=0.110$ and 0.112 , respectively).

Table 7. Distribution offers and negotiation failure in case of unequal contributions.

\begin{tabular}{|c|c|c|c|c|c|}
\hline & & $\begin{array}{c}\text { Equal Opportunities } \\
\text { Treatment }\end{array}$ & $\begin{array}{c}\text { Unequal } \\
\text { Incentives (Gain) }\end{array}$ & $\begin{array}{c}\text { Unequal } \\
\text { Incentives (Loss) }\end{array}$ & $\begin{array}{c}\text { Unequal } \\
\text { Opportunities }\end{array}$ \\
\hline \multirow{2}{*}{$\begin{array}{l}\text { All High } \\
\text { Contributors }\end{array}$} & Offer (St. Dev) & 77.94 (18.35) & $82.306(19.675)$ & $87.47(22.25)$ & $82.63(17.36)$ \\
\hline & Rejections/N & $3 / 34$ & $12 / 72$ & $6 / 47$ & $5 / 40$ \\
\hline \multirow{2}{*}{$\begin{array}{c}\text { Relevant } \\
\text { Subsamples }\end{array}$} & Offer (St. Dev) & - & 79.84 (21.075) & $88.58(23.08)$ & 84.09 (16.93) \\
\hline & Rejections/N & - & $4 / 31$ & $5 / 31$ & $4 / 33$ \\
\hline \multirow{2}{*}{$\begin{array}{c}\text { All Low } \\
\text { Contributors }\end{array}$} & Offer (St. Dev) & $125.88(29.06)$ & $119.236(28.920)$ & $131.28(20.04)$ & $113.78(31.42)$ \\
\hline & Rejections/N & $7 / 34$ & $19 / 72$ & $5 / 47$ & $9 / 40$ \\
\hline \multirow{2}{*}{$\begin{array}{c}\text { Relevant } \\
\text { Subsamples }\end{array}$} & Offer (St. Dev) & - & 125 (28.255) & $129.84(19.85)$ & $114.42(28.56)$ \\
\hline & Rejections/N & - & $6 / 31$ & $4 / 31$ & $5 / 33$ \\
\hline
\end{tabular}

The bold numbers show those groups that constitute the key samples for our treatment comparisons. Followers are subjects who decide in line with the incentives.

High contributors in the Loss Treatment make the most generous offers. These offers are significantly higher than the respective offers in the Equal Opportunities Treatments $(p=0.017)$. 
Hence, these high contributors either expect higher minimum claims than actually occurred or they think that unequal incentives in this context allow for a more egalitarian distribution. Meanwhile, low contributors in the Loss Treatment also make the highest offers. They are significantly higher than in the Unequal Opportunities Treatment and the Gain Treatment ( $p=0.018$ and 0.075 , respectively). These offers therefore do not reflect the responsibility argument at all. The table also includes the rejections rates of offers, that is, the number of offers below the minimum demand of the other group member. Here the treatments show no significant differences in bargaining failure.

In line with the predictions, the first result in Section 4.1 showed that a relatively small but substantial share of subjects in the Gain Treatment did not follow the incentives. Hence, some high contributors met low contributors who followed the incentives while others met low contributors who did not. The assignment was random. Moreover, we also know how the high contributors would have responded to the incentives if they had been affected by them.

The upper part of Table 8 shows that high contributors made a more generous offer if the other person did not follow the incentives. The difference is significant for a comparison with the Equal Opportunities Treatment $(p<0.017)$. Since these specific low contributors had exactly the same opportunities this difference is not in line with status considerations as in Cox et al. [29] but reflect differences in perceived kindness as in Levine [32] or Falk and Fischbacher [12]. The lower part of Table 8 provides an interesting qualification here. It reveals that differences in offers strongly depend on the (ex-post hypothetical) choices of the high contributor and her own fairness considerations here. If the high contributor did not choose to follow the incentives the offers do not differentiate. However, high contributors who followed the incentives provide a particularly generous offer for low contributors who behaved differently $(p=0.026)$. This difference in offers suggests that only followers attach a normative dimension to the (non-)pursuit of incentives (and might feel guilty about their own behavior) while non-followers just have a somewhat higher general propensity for generosity.

Table 8. Distribution offers and Negotiation Failure of High Contributors in the Gain Treatment in case of unequal contributions, differentiated for followers and non-followers among high and low contributors.

\begin{tabular}{|c|c|c|c|c|c|}
\hline & \multirow{3}{*}{$\begin{array}{c}\text { Equal Opportunities } \\
\text { Treatment }\end{array}$} & \multicolumn{4}{|c|}{ Unequal Incentives (Gain) } \\
\hline & & \multicolumn{4}{|c|}{ Low Contributor Is A } \\
\hline & & \multicolumn{2}{|c|}{ Follower } & \multicolumn{2}{|c|}{ Non-Follower } \\
\hline Offer (St. Dev) & $77.94(18.35)$ & \multicolumn{2}{|c|}{$79.84(21.08)$} & \multicolumn{2}{|c|}{$90.79(16.44)$} \\
\hline \multirow[t]{3}{*}{ Rejections/N } & $3 / 34$ & \multicolumn{2}{|c|}{$4 / 31$} & \multicolumn{2}{|c|}{$2 / 14$} \\
\hline & & \multicolumn{2}{|c|}{ High contributor is a } & \multicolumn{2}{|c|}{ High contributor is a } \\
\hline & & Follower & Non-Follower & Follower & Non-Follower \\
\hline \multicolumn{2}{|c|}{ Offer (St. Dev) } & $75.75(21.48)$ & $87.27(19.02)$ & $95.13(14.20)$ & 85 (18.71) \\
\hline \multicolumn{2}{|c|}{ Rejections/N } & $3 / 20$ & $1 / 11$ & $1 / 8$ & $1 / 6$ \\
\hline
\end{tabular}

Result 5: Offers of High Contributors in the Gain Treatment Do Not Take Considerations of Unequal Opportunities into Account

\section{Summary and Conclusions}

This paper has investigated whether people consider the random allocation of incentives and the resulting differences in contributions to a group account as unequal opportunities. The results show that this is not the case in situations in which the pursuit of incentives gives people an opportunity to become better off than the other group member. If following incentives avoids becoming worse off than the other group member some people with such incentives become more egalitarian.

The results have implications for our understanding of distributive justice. They suggest that people emphasize the possibility to choose rather strongly. If people decide to contribute less to a common pool their perceived entitlement decreases even if the decision has been efficient. The results 
are therefore more in line with a rather narrow interpretation of Konow's accountability criterion which implies that people are strictly accountable for the consequences of their decisions [13]. Few people apply the reasonability criterion of Roemer [11] which claims that people should not be accountable for making decisions that most people would consider as appropriate in the given context. The results contrast with the observation in Eisenkopf et al. [9] who found out that the randomly determined access to performance enhancing education (rather than incentives in this paper) induced relatively uneducated people to perceive outcome as a matter of luck.

Unequal incentives occur in many contexts. For example, most people are members of multiple working groups. Random processes from other contexts shape the incentives of these people to contribute to the benefit of a specific working group. Such unequal contributions can cause frictions within groups and people often ask low contributors to explain their behavior. The results in this paper show that information about the reasons for unequal contributions, and in particular about the type of incentive that influences the contributions, significantly influences the perception of distributive justice in the group. This holds both for high and low contributors.

On a more general level, the results also provide a behavioral insight into preferences for redistribution. Most people also accept a case for redistribution if luck determined the distribution of wealth [1,2]. This paper shows that this insight also extends to random assignment of 'negative' incentives. We obtain more egalitarian distributions if low contributors had to avoid personal hardship. But it does not extend to 'positive' incentives in which people can enrich themselves at the expense of others.

In this context it is interesting that the results did not reveal significant differences in bargaining failure across the treatments. This indicates that group members with different incentives and contributions do not disagree strongly about appropriate distributions. More specifically rather few people make offers that violate the perceived minimum entitlements of the other group member. Since unequal incentives in groups are often unavoidable the results suggest that people can resolve the underlying distribution problems rather amiably.

Funding: My former employer, the University of Konstanz, provided financial and logistical support for this project.

Acknowledgments: Two anonymous referees, Friedrich Breyer, Urs Fischbacher, Anja Schöttner, Matthias Uhl, Verena Utikal, my former colleagues at the Thurgau Institute of Economics and seminar participants at the University of Paderborn, the Technical University of Munich and the Colloquium on Personnel Economics in Cologne supported this project with multiple questions, suggestions and debates. The research assistants of the Lakelab and the Chair of Applied Economics at the University of Konstanz provided excellent support in conducting the experiment. All errors remain my own.

Conflicts of Interest: The author declares no conflict of interest.

Appendix A. Subsamples across the Treatments

Table A1. Number of groups in the different treatments and their subsamples.

\begin{tabular}{|c|c|c|c|c|}
\hline & $\begin{array}{c}\text { Equal } \\
\text { Opportunities }\end{array}$ & $\begin{array}{c}\text { Unequal } \\
\text { Incentives } \\
\text { (Gain) }\end{array}$ & $\begin{array}{c}\text { Unequal } \\
\text { Incentives } \\
\text { (Loss) }\end{array}$ & $\begin{array}{c}\text { Unequal } \\
\text { Opportunities }\end{array}$ \\
\hline Group account 300 points & 18 & 33 & 18 & 15 \\
\hline Groups with a follower. & - & 16 & 12 & - \\
\hline Groups without a follower. & - & 17 & 6 & - \\
\hline Group account 100 points & 18 & 33 & 18 & 15 \\
\hline Groups with a follower. & - & 27 & 16 & - \\
\hline Groups without a follower. & - & 6 & 2 & - \\
\hline
\end{tabular}


Table A1. Cont.

\begin{tabular}{|c|c|c|c|c|c|}
\hline & & $\begin{array}{c}\text { Equal } \\
\text { Opportunities }\end{array}$ & $\begin{array}{l}\text { Unequal } \\
\text { Incentives } \\
\text { (Gain) }\end{array}$ & $\begin{array}{l}\text { Unequal } \\
\text { Incentives } \\
\text { (Loss) }\end{array}$ & $\begin{array}{c}\text { Unequal } \\
\text { Opportunities }\end{array}$ \\
\hline \multicolumn{2}{|c|}{ Group account 200 points } & 34 & 72 & 47 & 40 \\
\hline \multirow{10}{*}{ Subsamples } & Disadvantaged member contributes 50 points. & - & - & - & 33 \\
\hline & Disadvantaged member contributes 150 points. & - & - & - & 7 \\
\hline & $\begin{array}{l}\text { Follower contributes } 50 \text { points. The follower has } \\
100 \text { points in her private account. }\end{array}$ & - & 31 & 31 & - \\
\hline & $\begin{array}{l}\text { Follower contributes } 150 \text { points. The follower } \\
\text { has } 100 \text { points in her private account. }\end{array}$ & - & 10 & 11 & - \\
\hline & $\begin{array}{l}\text { Non-Follower contributes } 50 \text { points. } \\
\text { The non-follower has } 0 \text { points in her } \\
\text { private account. }\end{array}$ & - & - & 4 & - \\
\hline & $\begin{array}{l}\text { Non-Follower contributes } 150 \text { points. } \\
\text { The non-follower has } 0 \text { points in her } \\
\text { private account. }\end{array}$ & - & - & 1 & - \\
\hline & $\begin{array}{l}\text { Follower contributes } 50 \text { points. The follower has } \\
1200 \text { points in her private account. }\end{array}$ & - & 5 & - & - \\
\hline & $\begin{array}{l}\text { Follower contributes } 150 \text { points. The follower } \\
\text { has } 1200 \text { points in her private account. }\end{array}$ & - & 1 & - & - \\
\hline & $\begin{array}{l}\text { Non-Follower contributes } 50 \text { points. } \\
\text { The non-follower has } 100 \text { points in her } \\
\text { private account. }\end{array}$ & - & 14 & - & - \\
\hline & $\begin{array}{l}\text { Non-Follower contributes } 150 \text { points. } \\
\text { The non-follower has } 100 \text { points in her } \\
\text { private account. }\end{array}$ & - & 11 & - & \\
\hline
\end{tabular}

The bold numbers show those groups that constitute the key samples for our treatment comparisons. Followers are subjects who decide in line with the incentives.

\section{Appendix B. Claims in Case of Equal Contributions}

This appendix shows the negotiation behavior when both group members make the same contributions (i.e., either 50 points per capita or 150 points per capita). Table A2 provides the information about the minimum claims of the different participants in these contexts. Non-parametric tests do not reveal any significant difference in claims across treatments or the different types of participants. Similarly, offers and incidences of negotiation failure do not show meaningful differences in these cases (results not reported in this paper). Hence unequal incentives or opportunities do not affect entitlements when both group members make the same effective contribution.

Table A2. Minimum demands in case of equal contributions.

\begin{tabular}{lcccc}
\hline & $\begin{array}{c}\text { Equal } \\
\text { Opportunities }\end{array}$ & $\begin{array}{c}\text { Unequal } \\
\text { Incentives (Gain) }\end{array}$ & $\begin{array}{c}\text { Unequal } \\
\text { Incentives (Loss) }\end{array}$ & $\begin{array}{c}\text { Unequal } \\
\text { Opportunities }\end{array}$ \\
\hline Average Claims & Group Account 300 points & & \\
\hline Regular & $117.31(40.92)$ & $117.80(40.21)$ & $114.17(45.82)$ & $110.37(44.90)$ \\
\hline Changed incentives/opportunities & - & $111.97(44.19)$ & $123.89(36.00)$ & $103.4(48.50)$ \\
\hline Followers & - & $123.63(35.52)$ & $104.44(53.16)$ & $117.33(41.48)$ \\
\hline Not followers & - & $115(41.47)$ & $97.5(55.78)$ & - \\
\hline \multicolumn{7}{l}{ Average Claims } & - & $131.765(27.667)$ & $118.33(49.16)$ & - \\
\hline Regular & Group Account 100 points & & $41.87(13.38)$ \\
\hline Changed incentives/opportunities & $45(10.82)$ & $44.39(12.63)$ & $43.75(18.92)$ & $41.07(15.88)$ \\
\hline Followers & - & $43.64(9.86)$ & $42.17(11.67)$ & $42.67(10.83)$ \\
\hline Not followers & - & $45.15(15.03)$ & $45.33(24.42)$ & - \\
\hline
\end{tabular}




\section{References}

1. Alesina, A.; Angeletos, G.M. Fairness and redistribution. Am. Econ. Rev. 2005, 95, 960-980. [CrossRef]

2. Alesina, A.; La, E. Ferrara Preferences for Redistribution in the Land of Opportunities. J. Public Econ. 2005, 89, 897-931. [CrossRef]

3. Burrows, P.; Loomes, G. The impact of fairness on bargaining. Empir. Econ. 1994, 19, 201-221. [CrossRef]

4. Hoffman, E.; McCabe, K.; Shachat, K.; Smith, V. Preferences, property rights, and anonymity in bargaining games. Games Econ. Behav. 1994, 7, 346-380. [CrossRef]

5. Ruffle, B.J. More is better, but fair is fair: Tipping in dictator and ultimatum games. Games Econ. Behav. 1998, 23, 247-265. [CrossRef]

6. Konow, J. Which is the fairest one of all? A positive analysis of justice theories. J. Econ. Lit. 2003, 41, 1188-1239. [CrossRef]

7. Durante, R.; Putterman, L. Preferences for Redistribution and Perception of Fairness: An Experimental Study; Working Papers; Sciences Po Publications: Paris, France, 2009.

8. Cappelen, A.W.; Hole, A.D.; Sørensen, E.; Tungodden, B. The pluralism of fairness ideals: An experimental approach. Am. Econ. Rev. 2007, 97, 818-827. [CrossRef]

9. Eisenkopf, G.; Fischbacher, U.; Föllmi-Heusi, F. Inequality of Opportunities and Distributive Justice. J. Econ. Behav. Organ. 2013, 93, 51-61. [CrossRef]

10. Bartling, B.; Fischbacher, U. Shifting the blame: On delegation and responsibility. Rev. Econ. Stud. 2012, 79, 67-87. [CrossRef]

11. Roemer, J.E. Equality of Opportunity; Harvard University Press: Cambridge, MA, USA, 1998.

12. Falk, A.; Fischbacher, U. A theory of reciprocity. Games Econ. Behav. 2006, 54, 293-315. [CrossRef]

13. Konow, J. Fair shares: Accountability and cognitive dissonance in allocation decisions. Am. Econ. Rev. 2000, 90, 1072-1091. [CrossRef]

14. Rubin, J.; Sheremeta, R. Principal-agent settings with random shocks. Manag. Sci. 2015, 62, $985-999$. [CrossRef]

15. Rey-Biel, P.; Sheremeta, R.M.; Uler, N. When Income Depends on Performance and Luck: The Effects of Culture and Information on Giving; MPRA Paper 83940; MPRA: Munich, Germany, 2018.

16. Reuben, E.; Rey-Biel, P.; Sapienza, P.; Zingales, L. The emergence of male leadership in competitive environments. J. Econ. Behav. Organ. 2012, 83, 111-117. [CrossRef]

17. Glöckner, A.; Irlenbusch, B.; Kube, S.; Nicklisch, A.; Normann, H.T. Leading With (Out) Sacrifice? A Public-Goods Experiment with A Privileged Player. Econ. Inq. 2011, 49, 591-597. [CrossRef]

18. Fuster, A.; Meier, S. Another hidden cost of incentives: The detrimental effect on norm enforcement. Manag. Sci. 2010, 56, 57-70. [CrossRef]

19. Cappelen, A.W.; Reme, B.-A.; Sørensen, E.Ø.; Tungodden, B. Leadership and incentives. Manag. Sci. 2015, 62, 1944-1953. [CrossRef]

20. Fischbacher, U. z-Tree: Zurich toolbox for ready-made economic experiments. Exp. Econ. 2007, 10, 171-178. [CrossRef]

21. Abeler, J.; Falk, A.; Götte, L.; Huffman, D. Reference points and effort provision. Am. Econ. Rev. 2011, 101, 470-492. [CrossRef]

22. Greiner, B. Subject Pool Recruitment Procedures: Organizing Experiments with ORSEE. J. Econ. Sci. Assoc. 2015, 1, 114-125. [CrossRef]

23. Fehr, E.; Schmidt, K.M. A Theory of Fairness, Competition, and Cooperation. Q. J. Econ. 1999, 114, 817-868. [CrossRef]

24. Bolton, G.E.; Ockenfels, A. ERC: A theory of equity, reciprocity, and competition. Am. Econ. Rev. 2000, 90, 166-193. [CrossRef]

25. Cherry, T.L.; Frykblom, P.; Shogren, J.F. Hardnose the dictator. Am. Econ. Rev. 2002, 92, 1218-1221. [CrossRef]

26. Oxoby, R.J.; Spraggon, J. Mine and yours: Property rights in dictator games. J. Econ. Behav. Organ. 2008, 65, 703-713. [CrossRef]

27. Lefgren, L.J.; Sims, D.P.; Stoddard, O.B. Effort, luck, and voting for redistribution. J. Public Econ. 2016, 143, 89-97. [CrossRef]

28. Tonin, M.; Vlassopoulos, M. Sharing one's fortune? An experimental study on earned income and giving. J. Behav. Exp. Econ. 2017, 66, 112-118. [CrossRef] 
29. Cox, J.C.; Friedman, D.; Gjerstad, S. A tractable model of reciprocity and fairness. Games Econ. Behav. 2007, 59, 17-45. [CrossRef]

30. McCabe, K.A.; Rigdon, M.L.; Smith, V.L. Positive reciprocity and intentions in trust games. J. Econ. Behav. Organ. 2003, 52, 267-275. [CrossRef]

31. Kern, M.C.; Chugh, D. Bounded ethicality: The perils of loss framing. Psychol. Sci. 2009, 20, 378-384. [CrossRef] [PubMed]

32. Levine, D.K. Modeling altruism and spitefulness in experiments. Rev. Econ. Dyn. 1998, 1, 593-622. [CrossRef]

(c) 